\title{
DYNAMICS OF ELASTIC HALF-SPACE WITH CYLINDRICAL CAVITY SUPPORTED BY SHELL AT AXYMMETRICAL LOADS
}

\author{
Zaporozhie National Technical University \\ 64, Zhukovsky Str., 69063, Zaporozhie,Ukraine, e-mail: antfas@ukr.net
}

Attention focusses on the study of a dynamic stressed-strained state of the linear-elastic isotropic homogeneous half-space, which contains the cylindrical cavity supported by a thin elastic shell, under the action of dynamic asymmetrical surface loads. The case, when the shell axis is perpendicular to the plane, which limits the half-space, is considered. The work goal is to study cross coupling the shell and a free surface of the half-space affected by non-stationary surface loads. The action of two types of asymmetrical surface loads is studied: the first load acts along the inner surface portion of the shell and the second load acts along the half-space surface portion. In both cases, loads depend on time as the unit Heaviside function. Up to now, the dynamic problems for shells in an elastic space have been considered only for an unlimited space, and the effects of a vertical plane supported by the shell have been omitted. Novelty in science is the consideration of cross coupling the shell and the free surface of the elastic half-space affected by dynamic surface loads. The finite element method has been applied to the study of the stressed-strained state of the mechanical system under consideration. The results obtained are graphically illustrated and analyzed.

Keywords: elastic half-space, thin cylindrical shell, asymmetrical dynamic problem, finite-element analysis.

1.Gorshkov A. G., Pozhuev V. I. Inertia-Based Plates and Shells at Mobile Loads. M.: Publishing House of MAI, 1992. $136 \mathrm{p}$.

2. Pozhuev V. I., Zhibitay Mohammed. Non-stationary reaction of cylindrical shell in elastic medium on asymmetrical moving load. Izvestia Vuzov. Stroitelstvo i Arkhitektura. 1991. No 6. P. 33 - 37.

3. Pozhuev V. I., Zhibitay Mohammed. Non-stationary oscillation of finite-length pipeline interacting with inertia medium on one side. Izvestia Vuzov. Stroitelstvo i Arkhitektura. 1992. No 4. P. $84-90$.

4. Pozhuev A. V., Fasolyak A. V. Non-stationary asymmetrical deformation of cylindrical shell through elastic space at moving surface loads. Novi Materialy i Tekhnologii v Metalergii ta Mashinobuduvanni. 2015. No 2. P. $108-114$.

5. Pozhuev A. V., Fasolyak A. V. Non-stationary deformation of cylindrical shell through elastic space at extended loads. Visnyk Zaporizkogo Natsionalnogo Universitetu. Fiziko-Matematychni Nauky. 2016. No 1. P. $200-213$.

6. Johnson E. R., Parnes R. Propagation of axisymmetric waves in an elastic half-space containing a cylindrical inclusion. Part I: formulation and general integral solution. Journal of Mechanical and Applied Mathematics. 1977. Vol. 30. No 3. P. $235-253$

7. Johnson E. R., Parnes R. Propagation of axisymmetric waves in an elastic half-space containing a cylindrical inclusion. Part II: Analysis of singularities, behavior of wave fronts and numerical results. Journal of Mechanical and Applied Mathematics. 1977. Vol. 30. No 3. P. 255 - 268.

8. Pozhuev V. I., Pozhuev A. V., Fasolyak A. V. Non-stationary deformation of cylindrical shell through elastic space at normal surface loads. Visnyk Zaporizkogo Natsionalnogo Universitetu. Fiziko-Matematychni Nauky. 2016. No 2. P. $170-183$

9. Obraztsov I. V., Saveliev L. M., Khazanov Ch. S. Finite-Element Analysis for Problems of Structural Mechanics of Flying Vehicles. M.: Vysshya Shkola, 1985. 393 p.

10. Segerlind l. Application of Finite-Element Analysis. M.: Mir, 1979. 393 p.

11. Pozhuev V. I., Pozhuev A. V., Fasolyak. Non-stationary deformation of cylindrical shell through elastic halfspace with free surface. Novi Materialy i Tekhnologii v Metalurgii ta Mashinobuduvanni. 2016. No 1. P. 119 -126 . 